\title{
Educação Profissional Técnica de Nível Médio em Saúde/Enfermagem no Sistema Único de Saúde
}

\author{
Middle-Level Technical Professional Education in Health/Nursing in the Unified Health System \\ Educación Profesional Técnica de Nivel Medio en Salud/Enfermería en el Sistema Único de Salud
}

Recebido: 04/08/2021 | Revisado: 09/08/2021 | Aceito: 10/08/2021 | Publicado: 14/08/2021

\author{
Adriana Katia Corrêa \\ ORCID: https://orcid.org/0000-0003-1496-6108 \\ Universidade de São Paulo, Brasil \\ E-mail: adricor@eerp.usp.br \\ Maria Conceição Bernardo de Mello e Souza \\ ORCID: https://orcid.org/0000-0001-7379-871X \\ Universidade de São Paulo, Brasil \\ E-mail: consouza@eerp.usp.br \\ Maria José Clapis \\ ORCID: https://orcid.org/0000-0002-2896-3808 \\ Universidade de São Paulo, Brasil \\ E-mail: maclapis@eerp.usp.br
}

\begin{abstract}
Resumo
Objetivo: apresentar e analisar um panorama da educação profissional técnica de nível médio na área da saúde, considerando cursos ofertados, matrículas e concluintes, no estado de São Paulo, de 2010 a 2015, com ênfase na enfermagem. Metodologia: pesquisa longitudinal, retrospectiva, caracterizada também como estudo de caso, fundamentado na perspectiva histórico-dialética, incluindo 24 cursos do Catálogo Nacional dos Cursos Técnicos (terceira versão), com base em dados do Instituto Nacional de Estudos e Pesquisas Educacionais Anísio Teixeira (INEP) - MEC, de 2010 a 2015. Resultados: foram ofertados 23 desses cursos, com aumento de oferta de 2010 a 2015. A enfermagem é o curso com mais oferta, matrículas e concluintes. A presença do setor privado e da modalidade subsequente é predominante. Conclusões: Essa conformação se fortalece no cenário político neoliberal, sendo contraditória à necessidade de formação que apoie o fortalecimento do SUS, a partir das necessidades sociais, bem como que promova emancipação do trabalhador.
\end{abstract}

Palavras-chave: Educação profissionalizante; Enfermagem; Sistema Único de Saúde; Formação profissional em saúde; Educação básica.

\begin{abstract}
Objective: to present and analyze an overview of high school technical professional education in the health area, considering courses offered, enrollments and graduates, in the state of São Paulo, from 2010 to 2015, with an emphasis on nursing. Methodology: longitudinal, retrospective research, also characterized as a case study, based on the historical-dialectical perspective, including 24 courses from the National Catalog of Technical Courses (third version), based on data from the National Institute of Educational Studies and Research Anísio Teixeira (INEP) MEC, from 2010 to 2015. Results: 23 of these courses were offered, with an increase in offer from 2010 to 2015. Nursing is the course with the most offer, enrollments and graduates. The presence of the private sector and the subsequent modality is predominant. Conclusions: This conformation is strengthened in the neoliberal political scenario, contradicting the need for training that supports the strengthening of the SUS, based on social needs, as well as promoting worker emancipation.
\end{abstract}

Keywords: Education, professional; Nursing; Unified Health System; Health human resource training; Education, primary and secondary.

\section{Resumen}

Objetivo: presentar y analizar un panorama da educación profesional técnica de nivel medio en el área de la salud, considerando cursos ofertados, matrículas y graduados, en el estado de São Paulo, de 2010 a 2015, con énfasis en la enfermería. Metodología: investigación longitudinal, retrospectiva, caracterizada tambien como estudio de caso fundamentado en la perspectiva histórico-dialética, incluyendo 24 cursos del Catálogo Nacional de los Cursos Técnicos (tercera versión), con base en datos del Instituto Nacional de Estudios e Investigaciones Educacionales Anísio Teixeira (INEP) - MEC, de 2010 a 2015. Resultados: fueron ofertados 23 de esos cursos, con aumento de oferta de 2010 a 2015. La enfermería es el curso con más ofertas, matrículas y concluyentes. La presencia del sector privado y de la modalidad subsecuente es predominante. Conclusiones: Esa conformación se fortalece en el escenário 
político neoliberal, siendo contradictória a la necesidad de formación que apoye el fortalecimiento del SUS, a partir de las necesidades sociales, bien como que promueva emancipación del trabajador.

Palabras clave: Educación profesionalizante; Enfermería; Sistema Único de Salud; Formación profesional en salud; Educación básica.

\section{Introdução}

O trabalho em saúde, que se configura como coletivo, historicamente, vem incorporando trabalhadores formados no nível superior de ensino, trabalhadores técnicos de nível médio, bem como trabalhadores com escolaridade até o ensino fundamental. Na internalidade da equipe de enfermagem, dados atuais referem-se a 432.146 auxiliares, 1.428 .845 técnicos e 609.846 Enfermeiros (Conselho Federal de Enfermagem - COFEN, 2020). Em âmbito mundial, o pessoal de enfermagem totaliza 27,9 milhões de pessoas, sendo 19,3 milhões (69\%) de enfermeiros e enfermeiras, seis milhões (22\%) de auxiliares de enfermagem e 2,6 milhões $(9 \%)$ que não se classificam nos grupos indicados (Organización Panamericana de la Salud/Organización Mundial de la Salud - OPS/OMS, 2020).

Se a equipe de enfermagem, no Brasil, constitui-se de mais de um milhão e oitocentos mil trabalhadores, equivalendo a mais da metade do contingente de trabalhadores em saúde, a presença de auxiliares e técnicos de enfermagem na equipe de saúde é representativa (Machado et al., 2016a). Nesse cenário é evidente, no Brasil, a relevância da atuação dos trabalhadores auxiliares e técnicos, com ênfase na enfermagem, no cenário do Sistema Único de Saúde (SUS), o que, dentre outros aspectos, demanda a necessidade de estudos e discussões acerca de sua formação. Acresce-se a isso a importância de contribuir com estudo sobre a conformação da educação profissional técnica de nível médio na área da saúde.

O foco deste artigo é a formação dos trabalhadores técnicos de nível médio da área da saúde. Enfocá-la implica em considerar criticamente o cenário marcado pelas políticas neoliberais, desde a década de 1990, e a conjuntura política que vem se conformando, sobretudo, desde 2016, marcada pela redução de direitos sociais já conquistados. Desde os anos 1990 , as políticas de educação profissional relacionam-se às políticas internacionais, de cunho neoliberal. Nessa lógica, avançam propostas que se consubstanciam em dispositivos político-legais e programas que tendem a restringir a educação do trabalhador para as demandas imediatas do mercado de trabalho e para a transmissão de ideias que fortaleçam o ideário neoliberal.

As contrarreformas no campo educacional vêm negando, à classe trabalhadora, a educação básica (incluindo a educação profissional técnica de nível médio) como direito subjetivo e universal. Elas têm relação com a associação da burguesia aos centros hegemônicos do capital, o que caracteriza, no Brasil, a sociedade capitalista dependente. Na atualidade, é necessária a compreensão crítica acerca, por exemplo, do congelamento dos investimentos públicos por 20 anos, favorecendo o mercado privado, das reformas trabalhistas e da previdência, de movimentos como o Escola sem Partido e o Todos pela Educação, enfim, propostas que fortalecem as más condições de vida da maioria da população, reafirmando a sociedade desigual (Ciavatta, 2019; Ramos \& Frigotto, 2017).

Na especificidade do campo da saúde, estão também presentes tensões entre interesses do mercado, que transformam saúde em mercadoria, com avanços substanciais da lógica privatizante no sistema de saúde, e o projeto societário, assumido pela Reforma Sanitária Brasileira, em defesa do SUS. Há de se destacar, pois, a luta permanente que se trava entre os interesses privatistas e o projeto de sustentação do SUS no Brasil. É nas inter-relações entre os avanços da lógica neoliberal e dos processos de lutas a favor das necessidades sociais, que também se insere a formação dos trabalhadores técnicos da área da saúde.

Este artigo é extraído de uma das etapas da pesquisa multicêntrica "Formação de Trabalhadores Técnicos em Saúde na Região das Américas" coordenada pela Escola Politécnica de Saúde Joaquim Venâncio/FIOCRUZ/RJ (Centro Colaborador da OMS para a educação de técnicos na saúde), na qual participaram, institucionalmente, as autoras deste artigo que foram 
responsáveis pela coleta e análise de dados relativos ao estado de São Paulo. Há uma lacuna quanto à sistematização do panorama geral em termos de oferta, matrículas e concluintes na educação profissional técnica de nível médio na área da saúde no estado de São Paulo.

O presente artigo teve como objetivo apresentar e analisar um panorama da educação profissional técnica de nível médio na área da saúde, considerando cursos ofertados, matrículas e concluintes, no estado de São Paulo, de 2010 a 2015, com ênfase na enfermagem.

\section{Metodologia}

\subsection{Aspectos Éticos}

Este estudo utilizou-se de dados secundários estando dispensados os procedimentos éticos de estudo com seres humanos.

\subsection{Desenho, período e local}

Estudo longitudinal e retrospectivo. Trata-se de estudo de caso (Estrela, 2018), que permite uma aproximação à conformação, em alguns aspectos, da educação profissional técnica de nível médio em enfermagem no estado de São Paulo, com enfoque exploratório centrado, no momento, na dimensão quantitativa. Fundamenta-se também na perspectiva históricodialética (Ramos, 2009).

Este artigo, que configura parte da etapa quantitativa de projeto mais amplo de pesquisa, sistematiza e analisa dados secundários sobre algumas dimensões relativas à organização da formação de trabalhadores técnicos em saúde, envolvendo oferta de cursos, matrículas e concluintes, considerando ainda, a natureza jurídica das instituições formadoras, no estado de São Paulo. Portanto, é estudo que enfoca dados específicos do campo educacional articulados às especificidades da saúde/enfermagem.

\subsection{Critérios de Inclusão e Exclusão}

Partiu-se do Catálogo Nacional dos Cursos Técnicos (CNCT), em sua terceira edição (Ministério da Educação, 2016), para a seleção dos cursos. Esse Catálogo é organizado em 13 eixos, sendo um deles denominado "Ambiente e Saúde" que se compõe de 28 cursos. Foram incluídos 24 desses cursos, considerando de modo estrito a área da saúde. Foram excluídos: Técnico em Meio Ambiente, Técnico em Controle ambiental, Técnico em Meteorologia e Reciclagem.

\subsection{Amostra}

Foram utilizadas as bases de dados do Instituto Nacional de Estudos e Pesquisas Educacionais Anísio Teixeira (INEP) do Ministério da Educação - Censo Escolar - dos anos de 2010 a 2015, para a coleta de dados de todos os cursos técnicos da área da saúde, incluídos neste estudo, ofertados, no período estipulado. Os dados do Censo Escolar/INEP compõem uma série histórica disponível a partir de 1995, tendo os seguintes aspectos positivos para a utilização como fonte para pesquisa: sua periodicidade anual, disponibilidade da série histórica contínua e organização dos cursos a partir do padrão do Catálogo Nacional dos Cursos Técnicos. Cabe ainda considerar que os dados desse Censo são fundamentais para a formulação e avaliação de políticas educacionais.

\subsection{Análise dos Resultados e Estatística}

A partir dos dados do Censo Escolar/INEP, foi construído um banco de dados, pela equipe coordenadora, com sistematização de informações pertinentes ao estudo Multicêntrico, sendo utilizadas medidas descritivas, apresentadas em 
tabelas de frequência. Este estudo parte desse banco, enfocando o estado de São Paulo, sendo os dados analisados à luz de uma perspectiva teórica que considera a educação profissional técnica de nível médio em suas relações com a totalidade social mais ampla:

A educação profissional em saúde é, pois, na perspectiva histórico-dialética “(...) considerada como uma mediação específica da formação humana na totalidade das relações sociais (...)”. As práticas instituídas não comportam neutralidade nem são estáticas, tendo sim fundamento filosófico e ideológico que carrega dada concepção de mundo e um projeto de sociedade. (Ramos, 2009, pp. 154-515).

\section{Resultados}

No Estado de São Paulo, foram ofertados 23 cursos técnicos da área da saúde. Considerando a opção deste estudo de enfocar, dentre os 28 cursos indicados no Catálogo Nacional de Cursos Técnicos (CNCT), no eixo ambiente e saúde (Ministério da Educação, 2016), os 24 ligados estritamente à área, o único não ofertado, nesse Estado, foi o de necropsia. Em cada ano deste estudo, foram ofertados, no total: em 2010, 1068 cursos; em 2011, 1058; em 2012, 944; em 2013, 934; em 2014, 1.104 e em, 2015, 1.139. Nos anos de 2012 e 2013, houve diminuição na oferta. Em 2013, comparando com dados de 2010, houve diminuição de 12,5\%. Entretanto, comparando 2010 e 2015, houve aumento de 6,6\% na oferta total dos cursos técnicos na área da saúde.

A enfermagem manteve a liderança na oferta em todos os anos, todavia, comparando 2010 e 2015, a oferta desse curso diminuiu $8,5 \%$. A oferta do curso de radiologia, que ocupou a segunda posição em todos os anos, teve decréscimo de 9,6\%. Exceto no ano de 2010, no qual o curso de farmácia teve oferta maior, estética ocupou a terceira posição na oferta de cursos, em todos os anos. O curso de nutrição e dietética ocupou a quinta posição, nos anos de 2010 a 2013, sendo que, em 2014 e 2015, passou a ocupar a quarta posição até então ocupada pelo curso de farmácia. A Tabela 1 a seguir expressa os cursos técnicos que foram mais ofertados no Estado, ano a ano.

Tabela 1 - Cursos técnicos selecionados no eixo ambiente e saúde, segundo o Catálogo Nacional dos Cursos Técnicos (CNCT), mais ofertados no Estado de São Paulo, em todas as modalidades, 2010-2015.

\begin{tabular}{|c|c|c|c|c|c|c|c|c|c|c|c|c|}
\hline \multirow{2}{*}{ Cursos } & \multicolumn{2}{|c|}{2010} & \multicolumn{2}{|c|}{2011} & \multicolumn{2}{|c|}{2012} & \multicolumn{2}{|c|}{2013} & \multicolumn{2}{|c|}{2014} & \multicolumn{2}{|c|}{2015} \\
\hline & $\mathbf{N}$ & $\%$ & $\mathbf{N}$ & $\%$ & $\mathbf{N}$ & $\%$ & $\mathbf{N}$ & $\%$ & $\mathbf{N}$ & $\%$ & $\mathbf{N}$ & $\%$ \\
\hline Enfermagem & 448 & $41,9 \%$ & 428 & $40,5 \%$ & 378 & $40,0 \%$ & 350 & $37,5 \%$ & 370 & $33,5 \%$ & 410 & $36,0 \%$ \\
\hline Radiologia & 156 & $14,6 \%$ & 161 & $15,2 \%$ & 150 & $15,9 \%$ & 149 & $16,0 \%$ & 152 & $13,8 \%$ & 141 & $12,4 \%$ \\
\hline Estética & 93 & $8,7 \%$ & 102 & $9,6 \%$ & 90 & $9,5 \%$ & 94 & $10,1 \%$ & 99 & $9,0 \%$ & 92 & $8,1 \%$ \\
\hline Farmácia & 103 & $9,6 \%$ & 93 & $8,8 \%$ & 74 & $7,8 \%$ & 73 & $7,8 \%$ & 85 & $7,7 \%$ & 82 & $7,2 \%$ \\
\hline $\begin{array}{l}\text { Nutrição e } \\
\text { Dietética }\end{array}$ & 66 & $6,2 \%$ & 57 & $5,4 \%$ & 52 & $5,5 \%$ & 70 & $7,5 \%$ & 93 & $8,4 \%$ & 103 & $9,0 \%$ \\
\hline
\end{tabular}

Fonte: Instituto Nacional de Estudos e Pesquisas Educacionais Anísio Teixeira - INEP (2010-2015).

Quanto à modalidade de oferta, apreende-se que, em todos os anos, predominou a oferta de cursos técnicos na modalidade subsequente, atingindo $94,5 \%$ em 2013. Apesar de pequenas oscilações, houve aumento da oferta de 7,8\%, comparando dados de 2010 e 2015 . As modalidades integrada e concomitante foram bem menos expressivas. A primeira teve maior oferta, no período estudado, em 2015, equivalendo a 4,6\% e a segunda em 2010, com 7,1\%. A oferta de cursos na modalidade integrada ampliou, em 136,3\%, passando de 22 cursos, em 2010, para 52, em 2015. Essa modalidade, em 2014 e 2015, teve oferta superior à concomitante. No Estado, a oferta de EJA foi mínima. Esses dados podem ser vistos na Tabela 2. 
Tabela 2 - Número de cursos técnicos selecionados no eixo ambiente e saúde, segundo o Catálogo Nacional dos Cursos Técnicos (CNCT), por modalidade e ano de oferta, São Paulo, 2010-2015.

\begin{tabular}{|c|c|c|c|c|c|c|c|c|c|c|c|c|}
\hline \multirow{2}{*}{$\begin{array}{c}\text { Modalidade de } \\
\text { Oferta }\end{array}$} & \multicolumn{2}{|c|}{2010} & \multicolumn{2}{|c|}{2011} & \multicolumn{2}{|c|}{2012} & \multicolumn{2}{|c|}{2013} & \multicolumn{2}{|c|}{2014} & \multicolumn{2}{|c|}{2015} \\
\hline & $\mathbf{N}$ & $\%$ & $\mathbf{N}$ & $\%$ & $\mathbf{N}$ & $\%$ & $\mathbf{N}$ & $\%$ & $\mathbf{N}$ & $\%$ & $\mathbf{N}$ & $\%$ \\
\hline Integrado & 22 & $2,1 \%$ & 8 &, $8 \%$ & 23 & $2,4 \%$ & 22 & $2,4 \%$ & 47 & $4,3 \%$ & 52 & $4,6 \%$ \\
\hline Concomitante & 76 & $7,1 \%$ & 62 & $5,9 \%$ & 35 & $3,7 \%$ & 29 & $3,1 \%$ & 35 & $3,2 \%$ & 41 & $3,6 \%$ \\
\hline Subsequente & 970 & $90,8 \%$ & 988 & $93,4 \%$ & 886 & $93,9 \%$ & 883 & $94,5 \%$ & 1017 & $92,1 \%$ & 1046 & $91,8 \%$ \\
\hline $\begin{array}{l}\text { EJA presencial } \\
\text { Integrado } \\
\text { EJA }\end{array}$ & 0 & $0,0 \%$ & 0 & $0,0 \%$ & 0 & $0,0 \%$ & 0 & $0,0 \%$ & 5 &, $5 \%$ & 0 & $0,0 \%$ \\
\hline $\begin{array}{l}\text { semipresencial } \\
\text { Integrado }\end{array}$ & 0 & $0,0 \%$ & 0 & $0,0 \%$ & 0 & $0,0 \%$ & 0 & $0,0 \%$ & 0 & $0,0 \%$ & 0 & $0,0 \%$ \\
\hline
\end{tabular}

Fonte: Instituto Nacional de Estudos e Pesquisas Educacionais Anísio Teixeira - INEP (2010-2015).

Ainda em relação às modalidades de oferta, considerando os cursos, nutrição e dietética foi o que mais teve oferta na modalidade integrada, com destaque para os anos de 2015, com 42 cursos (40,81\%). Radiologia foi o único curso que não teve oferta, nessa modalidade, no período. O curso de enfermagem assim se apresentou, em relação à oferta na modalidade integrada: 2 cursos (4\%) em 2010; 2 (0,5\%) em 2011; 3 (0,8\%) em 2012; 1 (0,3\%), em 2013; $3(0,8 \%)$ em 2014 e 3 (0,8\%) em 2015. No que se refere especificamente à modalidade concomitante, considerando a porcentagem de oferta de cada curso, exceto em 2010, farmácia foi o mais ofertado, sendo que, em 2011, essa oferta representou 11 cursos (11,8\% do total de oferta desse curso). Em 2010, a enfermagem foi o curso que mais teve oferta concomitante, correspondendo a 41 cursos $(9,2 \%$ do total de cursos de enfermagem). Esses dados podem ser acompanhados na Tabela 3. 
Tabela 3 - Cursos técnicos selecionados no eixo ambiente e saúde, segundo o Catálogo Nacional dos Cursos Técnicos $(\mathrm{CNCT})$, mais ofertados no Estado de São Paulo, por modalidade de oferta e ano, 2010-2015.

\begin{tabular}{|c|c|c|c|c|c|c|c|c|c|c|c|}
\hline \multirow{2}{*}{ Ano } & \multirow{2}{*}{$\begin{array}{l}\text { Modalidade de } \\
\text { Oferta }\end{array}$} & \multicolumn{2}{|c|}{ Enfermagem } & \multicolumn{2}{|c|}{ Estética } & \multicolumn{2}{|c|}{ Farmácia } & \multicolumn{2}{|c|}{$\begin{array}{l}\text { Nutrição e } \\
\text { Dietética }\end{array}$} & \multicolumn{2}{|c|}{ Radiologia } \\
\hline & & $\mathbf{N}$ & $\%$ & $\mathbf{N}$ & $\%$ & $\mathbf{N}$ & $\%$ & $\mathbf{N}$ & $\%$ & $\mathbf{N}$ & $\%$ \\
\hline \multirow{3}{*}{2010} & Integrado & 2 & ,4 & 2 & 2,2 & 3 & 2,9 & 8 & 12,1 & 0 & 0,0 \\
\hline & Concomitante & 41 & 9,2 & 5 & 5,4 & 9 & 8,7 & 6 & 9,1 & 0 & 0,0 \\
\hline & Subsequente & 405 & 90,4 & 86 & 92,5 & 91 & 88,3 & 52 & 78,8 & 156 & 100,0 \\
\hline \multirow{3}{*}{2011} & Integrado & 2 &, 5 & 1 & 1,0 & 0 & 0,0 & 2 & 3,5 & 0 & 0,0 \\
\hline & Concomitante & 24 & 5,6 & 7 & 6,9 & 11 & 11,8 & 3 & 5,3 & 2 & 1,2 \\
\hline & Subsequente & 402 & 93,9 & 94 & 92,2 & 82 & 88,2 & 52 & 91,2 & 159 & 98,8 \\
\hline \multirow{3}{*}{2012} & Integrado & 3 & ,8 & 1 & 1,1 & 1 & 1,4 & 10 & 19,2 & 0 & 0,0 \\
\hline & Concomitante & 12 & 3,2 & 4 & 4,4 & 4 & 5,4 & 2 & 3,8 & 0 & 0,0 \\
\hline & Subsequente & 363 & 96,0 & 85 & 94,4 & 69 & 93,2 & 40 & 76,9 & 150 & 100,0 \\
\hline \multirow{3}{*}{2013} & Integrado & 1 &, 3 & 0 & 0,0 & 0 & 0,0 & 18 & 25,7 & 0 & 0,0 \\
\hline & Concomitante & 5 & 1,4 & 2 & 2,1 & 5 & 6,8 & 4 & 5,7 & 0 & 0,0 \\
\hline & Subsequente & 344 & 98,3 & 92 & 97,2 & 68 & 93,2 & 48 & 68,6 & 149 & 100 \\
\hline \multirow{5}{*}{2014} & Integrado & 3 &, 8 & 0 & 0,0 & 4 & 4,7 & 33 & 35,5 & 0 & 0,0 \\
\hline & Concomitante & 9 & 2,4 & 3 & 3,0 & 6 & 7,1 & 6 & 6,5 & 1 & 7 \\
\hline & Subsequente & 357 & 96,5 & 96 & 97,0 & 75 & 88,2 & 54 & 58,1 & 151 & 99,3 \\
\hline & $\begin{array}{l}\text { EJA presencial } \\
\text { Integrado }\end{array}$ & 1 &, 3 & 0 & 0,0 & 0 & 0,0 & 0 & 0,0 & 0 & 0,0 \\
\hline & $\begin{array}{l}\text { EJA } \\
\text { semipresencial } \\
\text { Integrado }\end{array}$ & 0 & 0,0 & 0 & 0,0 & 0 & 0,0 & 0 & 0,0 & 0 & 0,0 \\
\hline \multirow{5}{*}{2015} & Integrado & 3 &, 7 & 0 & 0,0 & 2 & 2,4 & 42 & 40,8 & 0 & 0,0 \\
\hline & Concomitante & 15 & 3,7 & 4 & 4,3 & 4 & 4,9 & 4 & 3,9 & 0 & 0,0 \\
\hline & Subsequente & 392 & 95,6 & 88 & 9,7 & 76 & 92,7 & 57 & 55,3 & 141 & 100,0 \\
\hline & $\begin{array}{l}\text { EJA presencial } \\
\text { Integrado }\end{array}$ & 0 & 0,0 & 0 & 0,0 & 0 & 0,0 & 0 & 0,0 & 0 & 0,0 \\
\hline & $\begin{array}{l}\text { EJA } \\
\text { semipresencial } \\
\text { Integrado }\end{array}$ & 0 & 0,0 & 0 & 0,0 & 0 & 0,0 & 0 & 0,0 & 0 & 0,0 \\
\hline
\end{tabular}

Fonte: Instituto Nacional de Estudos e Pesquisas Educacionais Anísio Teixeira - INEP (2010-2015).

O número total de matrículas nos 23 cursos ofertados no Estado de São Paulo variou de 50.022, em 2013, a 72.113 em 2010. Observa-se, pois, uma tendência de diminuição de matrículas de 2010 a 2013 e aumento a partir de 2014 . Do mesmo modo que a oferta, a maioria de matrículas foi também nos cursos de enfermagem, alcançando, em $2010,41.760$ matrículas $(57,9 \%)$. Em todos os anos estudados, o curso que ocupou a segunda posição foi radiologia que atingiu, em 2013, 19,2\% das matriculas. Estética, em todos os anos, foi o curso que ocupou a terceira posição no número de matrículas, sendo o maior percentual em 2013 (9,2\%). Os cursos de farmácia e nutrição e dietética ocuparam, respectivamente, a quarta e quinta posições, em 2010, 2012 e 2013, o que se inverteu nos anos 2014 e 2015. Em 2011, o curso de massoterapia esteve na quinta posição no número de matrículas $(4,1 \%)$. Esses dados estão apresentados na Tabela 4. 
Tabela 4 - Cursos técnicos selecionados no eixo ambiente e saúde, segundo o Catálogo Nacional Cursos Técnicos (CNCT), com maior número de matrículas, São Paulo, 2010-2015.

\begin{tabular}{lcccccc}
\hline & Ano & & & & & \\
\\
Matricula & $\mathbf{2 0 1 0}$ & $\mathbf{2 0 1 1}$ & $\mathbf{2 0 1 2}$ & $\mathbf{2 0 1 3}$ & $\mathbf{2 0 1 4}$ & $\mathbf{2 0 1 5}$ \\
Curso & & & & & \\
\hline Enfermagem & 41760 & 40045 & 25805 & 23139 & 26209 & 30740 \\
& $(57,9 \%)$ & $(57,2 \%)$ & $(49,0 \%)$ & $(46,3 \%)$ & $(40,7 \%)$ & $(45,0 \%)$ \\
Radiologia & 10281 & 9876 & 9695 & 9591 & 11469 & 10770 \\
& $(14,3 \%)$ & $(14,1 \%)$ & $(18,4 \%)$ & $(19,2 \%)$ & $(17,8 \%)$ & $(15,8 \%)$ \\
Estética & 4989 & 5055 & 4165 & 4624 & 5299 & 5387 \\
& $(6,9 \%)$ & $(7,2 \%)$ & $(7,9 \%)$ & $(9,2 \%)$ & $(8,2 \%)$ & $(7,9 \%)$ \\
Farmácia & 4312 & 3502 & 2728 & 2599 & 3744 & 3618 \\
& $(6,0 \%)$ & $(5,0 \%)$ & $(5,2 \%)$ & $(5,2 \%)$ & $(5,8 \%)$ & $(5,3 \%)$ \\
Nutrição e Dietética & 2547 & 2293 & 2315 & 2300 & 3798 & 4324 \\
& $(3,5 \%)$ & $(3,3 \%)$ & $(4,4 \%)$ & $(4,6 \%)$ & $(5,9 \%)$ & $(6,3 \%)$ \\
Massoterapia & 1436 & 2888 & 1447 & 1330 & 2250 & 2862 \\
& $(2,0 \%)$ & $(4,1 \%)$ & $(2,7 \%)$ & $(2,7 \%)$ & $(3,5 \%)$ & $(4,2 \%)$ \\
\hline
\end{tabular}

Fonte: Instituto Nacional de Estudos e Pesquisas Educacionais Anísio Teixeira - INEP (2010-2015).

Quanto aos concluintes, os dados obtidos foram até 2014. Verifica-se que, no período estudado, concluíram os cursos um total de 89.226 alunos (período 2010-2014). Concluíram curso de enfermagem (2010-2014) - 50.410 (56,5\%) alunos, 11.839 (13,26\%) na radiologia, 5.591 (6,26\%) concluintes no curso de estética, 5.156 (5,8\%) na farmácia, 3.391 (3,8\%) no curso de nutrição e dietética, $2.821(3,16)$ alunos concluíram análises clínicas, $2.250(2,52 \%)$ prótese dentária e 1.991 $(2,23 \%)$ saúde bucal.

De 2010 a 2015, no Estado de São Paulo, conforme gráfico a seguir, predominou oferta de cursos pela dependência administrativa privada, com pequenas oscilações no percentual dessa oferta. Todos os cursos que compõem foram ofertados pela esfera privada. Comparando os anos de 2010 e 2015, essa oferta passou de 91,8\% para 88\%; 2011 é o ano com maior porcentagem de oferta de cursos técnicos por essa dependência administrativa $-91,9 \%$.

Em relação à oferta estadual, comparando 2010 e 2015, houve incremento de 6,5\% para 9,7\% da oferta, sendo que 2013 foi o ano com maior porcentagem - 10,2\%. A oferta municipal é a menor em todos os anos, comparando com a oferta estadual e privada, mas aumentou de 1,8\% (2010) para 2,3\% (2015). Não há oferta de cursos técnicos da área da saúde na rede federal, o que pode ser visualizado no Gráfico 1. 
Gráfico 1 - Número de cursos técnicos selecionados no eixo ambiente e saúde, a partir do Catálogo Nacional dos Cursos Técnicos (CNCT), segundo dependência administrativa, São Paulo, 2010 - 2015.

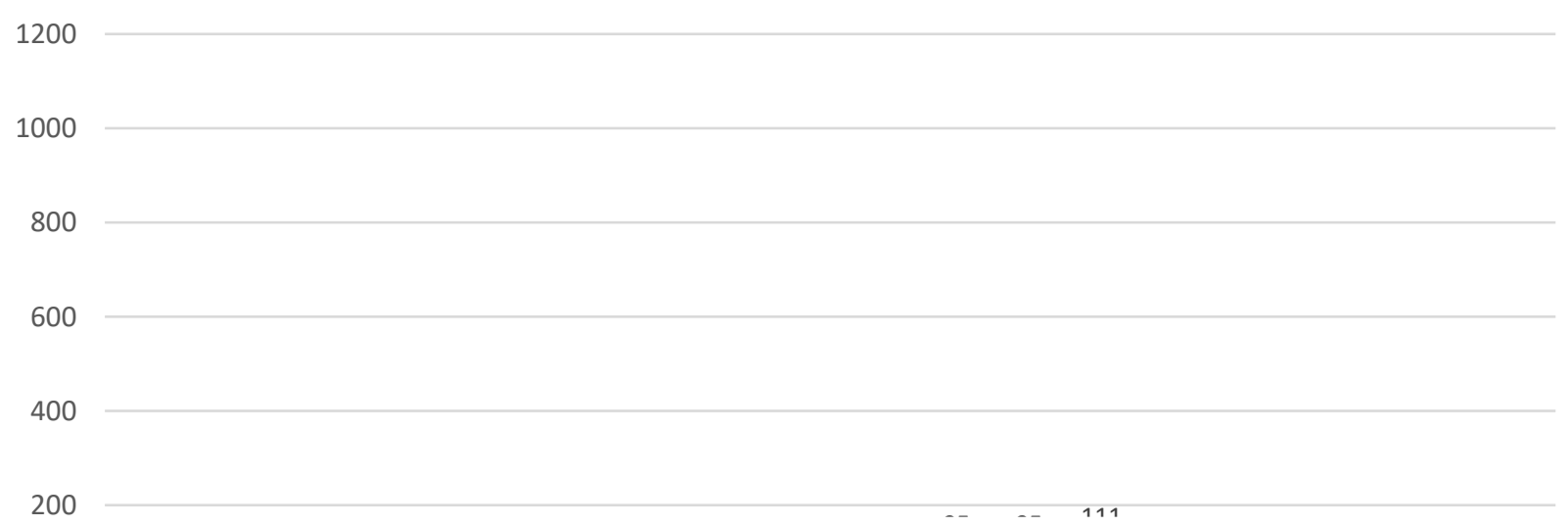

Fonte: Instituto Nacional de Estudos e Pesquisas Educacionais Anísio Teixeira - INEP (2010-2015).

Considerando as matrículas nas esferas estadual, municipal e privada, no Estado de São Paulo, de 2010 a 2015, o maior número de matrículas ocorreu, em todo o período, na dependência administrativa privada. Em 2011, as matrículas nessa dependência administrativa representaram (64.750) 92,5\% do total. Nesse período, também houve aumento do número de matrículas na dependência administrativa estadual: em 2010, essa esfera tem 3.685 (5,1\% do total de matrículas do ano) e, em 2013, 8,3\% (4.149 matrículas). Cabe destacar que, comparando 2010 e 2015, houve aumento de 29\% no número de matrículas na dependência administrativa pública estadual, indo de 3.685 para 4.770. As matrículas na rede municipal ficaram em torno de 2,2\%, em 2011, a 2,9\% em 2013. Não havendo oferta, não ocorreu matrícula na rede federal, conforme representado no Gráfico 2. 
Gráfico 2 - Distribuição do número de matrículas nos cursos selecionados no eixo ambiente e saúde, segundo o Catálogo Nacional dos Cursos Técnicos (CNCT), segundo dependência administrativa, São Paulo, 2010 a 2015.

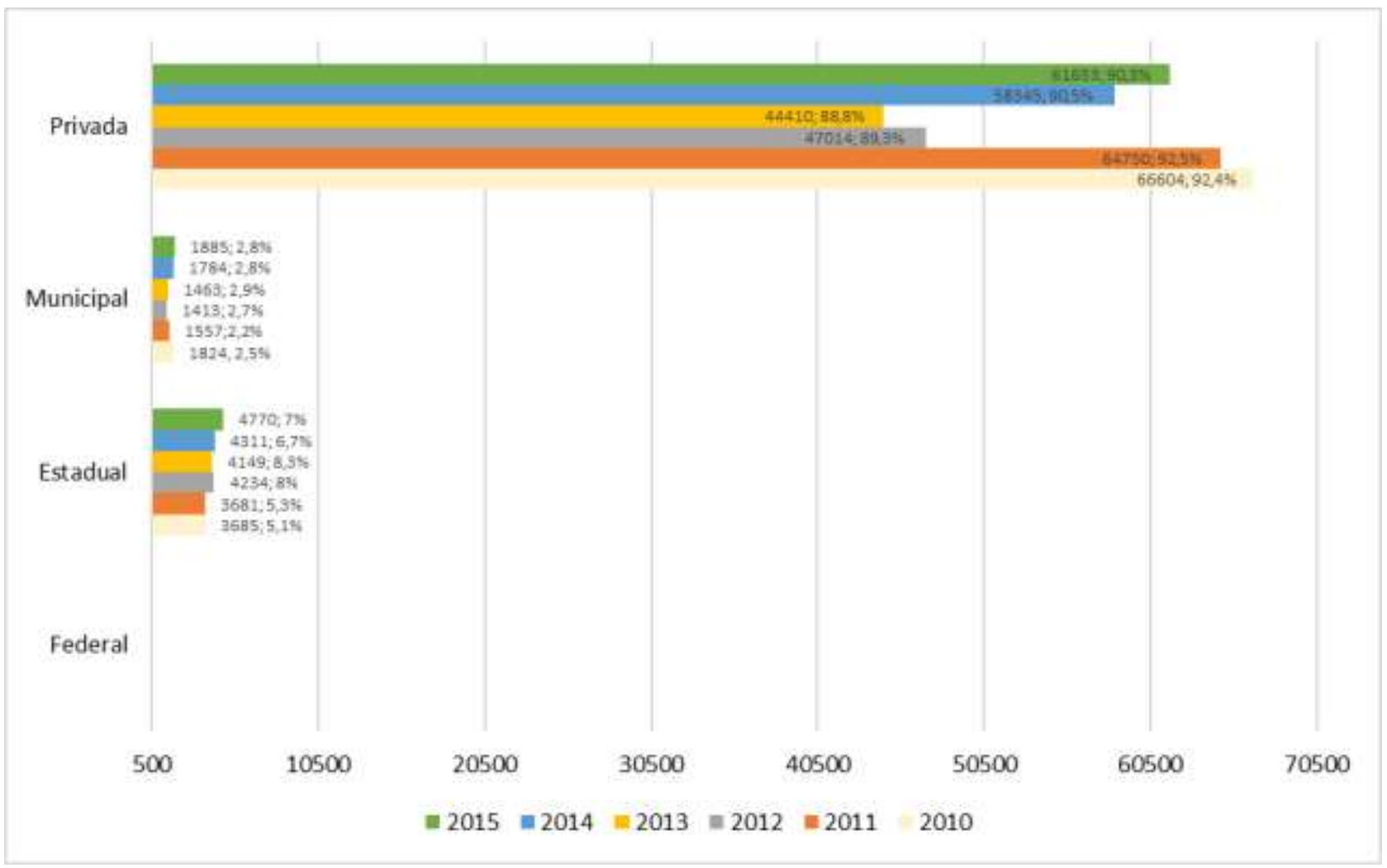

Fonte: Instituto Nacional de Estudos e Pesquisas Educacionais Anísio Teixeira - INEP (2010-2015).

No Estado de São Paulo, foi na dependência administrativa privada que esteve o maior número de concluintes: 77.051 (86,3\%), seguido de $7.809(8,7 \%)$ referentes à dependência administrativa estadual. O Estado não ofereceu cursos na esfera federal, assim, não teve concluintes nessa esfera administrativa.

Quanto aos cursos ofertados na categoria privada particular, a enfermagem foi o curso com maior oferta em todo o período, seguida de radiologia, estética, farmácia, nutrição e dietética, nessa ordem. Em 2013 e 2015, alcança o percentual de 96,8\% de oferta nessa categoria. Quanto às matrículas, a enfermagem também foi o curso com maior número de matrículas na categoria privada particular em todo o período do estudo. Apesar disso, comparando 2010 e 2015, houve um decréscimo no número de matriculas desse curso da ordem de 26,4\%. O curso de radiologia ocupou o segundo lugar no número de matrículas e, comparando 2010 e 2015, teve aumento de $4,8 \%$.

É marcante a presença da modalidade subsequente, em todos os anos, na esfera privada. Em cada um dos anos, a porcentagem de oferta dessa modalidade de ensino pela entidade administrativa privada foi de 91,1\%, em 2010; 91,5\%, em 2011; 89,8\% em 2012; 89,7\% em 2013; 92,6\%, em 2014 e 92,2\% em 2015. A modalidade EJA presencial integrado também teve oferta maior pela esfera privada.

\section{Discussão}

No estado de São Paulo é expressiva a oferta de cursos de EPTNM na área da saúde. O oferecimento de todos os cursos, exceto necropsia, e o aumento da oferta, de 2010 para 2015, podem ser associados a alguns aspectos peculiares do estado como a extensa rede de atenção à saúde; a capacidade de empregabilidade na área; a ampla rede de escolas que ofertam cursos técnicos da área da saúde; o número expressivo de matrículas da educação profissional em geral que, provavelmente, no 
período deste estudo, também guarda relação com a realização de programas instituídos, no âmbito do estado, para formação de trabalhadores técnicos de nível médio, inserindo programa específico para a área da saúde e outros que também contemplaram essa área. A seguir, feitos alguns comentários acerca desses aspectos.

Considerando dados até 2018, o Estado de São Paulo tem a maior capacidade instalada vinculada ao SUS no Brasil, indicando uma vasta rede de atenção (Governo do Estado de São Paulo, 2019), que demanda atuação de trabalhadores técnicos. A rede de escolas que oferta educação profissional na área da saúde, no estado, também é ampla: no âmbito público, nível estadual, há o Centro Paula Souza e outras escolas estaduais, as Escolas Técnicas do SUS, escolas mantidas por universidade (UNICAMP) e por hospitais-escola públicos. Há também a presença de escolas municipais; além de ampla rede de escolas privadas.

Tendo em vista a capacidade de empregabilidade, na área da saúde, de todas as unidades da federação e do Distrito Federal, há concentração nos estados da Região Sudeste, com destaque para São Paulo (25,1\%); seguido do Rio de Janeiro, $(12,5 \%)$; Minas Gerais $(9,1 \%)$ (Machado, et al., 2016b). Compreende-se que essa capacidade de empregabilidade também influencie na oferta de cursos técnicos da área da saúde.

Em 2014, o número de matrículas na educação profissional foi da ordem de 396.826, o que representou $28.9 \%$ em relação ao Brasil - 1.374.569 de matrículas (Secretaria da Educação do Estado de São Paulo, 2014). Esse número segue em crescimento: o número total de matrículas da educação profissional, no estado de São Paulo, cresceu 1,6\% de 2015 a 2019, chegando a 428.283 matrículas em 2019 (Instituto Nacional de Estudos e Pesquisas Educacionais Anísio Teixeira - INEP, 2019).

Quanto aos programas instituídos, o Estado de São Paulo implementou o Programa de Formação de Profissionais de Nível Técnico para a Área de Saúde no Estado de São Paulo - TEC-Saúde (Assembléia Legislativa do Estado de São Paulo (SP), 2008)' específico para trabalhadores da enfermagem, e o Programa Rede Ensino Médio Técnico - RETEC (Secretária da Educação, 2011), em 2011 é substituído pelo VENCE, em 2012, programas gerais, tendo como foco ampliar o acesso de estudantes do Ensino Médio regular da rede estadual à educação profissional técnica, inserindo também a área da saúde, tendo relação, originalmente, com a meta de ampliar oferta nas modalidades concomitante e integrada. Foram realizados pela Secretaria da Educação em parceria com o Instituto Federal de Educação, Ciência e Tecnologia de São Paulo (IFSP) e o Centro Estadual de Educação Tecnológica Paula Souza, além das instituições de ensino técnico, incluindo escolas da rede privada.

Dentre os cursos do REDE e do VENCE estavam incluídos muitos da área da saúde. O curso técnico de enfermagem, tanto em 2011 como em 2012, ocupou o segundo lugar no número de matrículas (Secretaria da Educação do Estado de São Paulo, 2021). No estado de São Paulo, os dados do presente estudo mostram que, apesar da diminuição da oferta de curso técnico de enfermagem, comparando os anos de 2010 e 2015, essa área se mantém na liderança, também em termos de oferta, matrículas e concluintes.

Ambos os programas, REDE e VENCE, se inseriram no "Programa Educação - Compromisso de São Paulo" da Secretaria da Educação ${ }^{(15)}$. Esse último, iniciado em 2011, tem a intenção de colocar a rede estadual paulista entre os 25 melhores sistemas de educação do mundo, conforme os critérios internacionais, além de posicionar a carreira de professor entre as dez mais desejadas do Estado. O Rede e o Vence, inseridos no Programa Educação - Compromisso de São Paulo tiveram apoio e envolvimento de diversas organizações e instituições de cunho empresarial (Secretaria da Educação do Estado de São Paulo, 2021). Algumas dessas empresas fazem parte do "Todos pela Educação" (Todos pela Educação, 2021).

O "Todos pela Educação" (Ministerio da Educação, 2011) prevê a implementação de programas e ações de assistência técnica e financeira, visando a mobilização social pela melhoria da qualidade da educação básica, em âmbito federal, em colaboração com Municípios, Distrito Federal e Estados, e com a participação das famílias, além de organizações sindicais e da sociedade civil, fundações, entidades de classe empresariais, igrejas e entidades confessionais, pessoas físicas e jurídicas. 
Nesse documento fica explícita a lógica de encolhimento do Estado no que se refere às políticas públicas, um dos pilares do modelo neoliberal; além disso, as parcerias tendem a fortalecer a lógica privatizante no campo educacional, outro vértice fundamental desse modelo.

Nessa direção, cabe ressaltar que as matrículas da educação profissional, no estado de São Paulo, concentram-se na rede privada: em 2014, um dos anos deste estudo, representavam 59,8\% (Secretaria da Educação do Estado de São Paulo, 2014). A partir dos dados deste estudo, a área da saúde destaca-se, sobremaneira, na medida em que as matrículas, nessa esfera administrativa, no estado de São Paulo, chegam a 92,5\%, em 2011. O curso de enfermagem, em 2013 e 2015, alcança 96,8\% de matrículas na rede privada.

Essa realidade do estado de São Paulo vai de encontro ao proposto pelo Plano Estadual de Educação (Estado de São Paulo, 2016) de ampliar em 50\% as matrículas da educação profissional técnica de nível médio, sendo, pelo menos, 50\% no segmento público.

Já se faz presente, no século XXI, um processo avançado de privatização da educação brasileira. Enquanto nos anos 1990, houve avanço da privatização do ensino superior, atualmente essa privatização avança para a educação básica, envolvendo não apenas a ampliação das matrículas no setor privado, mas diversificações de ações na esfera pública. Coexistem confederações antigas conhecidas como mantenedoras de ensino até grupos empresariais abertos ao capital internacional (Melo \& Sousa, 2017).

Os dados deste estudo indicam também oferta, matrículas e concluintes, na educação profissional técnica de nível médio, na área da saúde, predominantemente na rede privada, em todo o período, com incremento da oferta de 2010 para 2015, sendo que todos os 23 cursos envolvidos foram ofertados por essa esfera administrativa, com ênfase na enfermagem. Mesmo com decréscimo de matrículas de enfermagem, na rede privada, de 2010 para 2015, da ordem de 26,4\%, essa se mantém na liderança em relação aos outros cursos. Outro dado importante deste estudo refere-se à inexistência de oferta de cursos técnicos da área da saúde na rede federal no estado de São Paulo. Nos institutos federais, o investimento se dá, prioritariamente, em cursos do setor industrial.

Dados nacionais também indicam o curso técnico de enfermagem dentre aqueles com maior número de matrículas, principalmente na rede privada na qual, em primeiro lugar, está o técnico de enfermagem, com 121.357 matrículas (17,6\%), seguido por Segurança do Trabalho, com 89.059 matriculas (12,9\%). Na rede pública, o curso de enfermagem ocupa a quinta posição, com 32.475 matrículas (4,3\%) (Instituto Nacional de Educação e Pesquisa Educacional Anísio Teixeira - INEP, 2014). Não é casual, a preferência do setor privado pelo curso técnico de enfermagem, pois representa uma oferta de baixo risco: os técnicos dessa área estão envolvidos de modo marcante na atenção em saúde, cabendo considerar que, por ano, são realizados, pelo SUS, cerca de 2,8 bilhões de atendimentos, em todos os níveis de atenção (Bonfim, Rummert, \& Goulart, 2017).

Tem-se, pois, uma contradição fundamental: a necessidade de solidificar um sistema público, na abrangência do SUS, em termos doutrinários e organizativos, contando, dentre outros aspectos de ordem financeira e de gestão, com atuação de trabalhadores com formação ético-política e técnica condizente aos preceitos do SUS, em cenário no qual predomina a oferta privada de cursos técnicos de nível médio. E, mesmo na vigência de propostas que fortaleceriam a oferta pública, como os programas destacados, há a abertura ao setor privado. "O que está em disputa, portanto, é a formação de trabalhadores técnicos, segundo as necessidades sociais do país ou as demandas do sistema capital" (Bonfim et al., 2017).

Considera-se relevante associar que o predomínio da entidade administrativa privada está associado também ao predomínio da modalidade subsequente, como mostrado nos resultados apresentados anteriormente. A partir dos dados deste estudo, a oferta subsequente ao ensino médio é predominante na área da saúde. A modalidade integrada teve, porém, maior oferta, no período estudado, em 2015. Apesar de mantida sempre em número muito menor, quando comparada aos valores da 
modalidade subsequente, a oferta dos cursos na modalidade integrada ampliou consideravelmente, inclusive, de 2010 para 2015, em 136,3\%, tendo provável relação com os programas de formação implementados. Na modalidade integrada, a presença da enfermagem é pouco expressiva, e, na concomitante, em um dos anos deste estudo, a enfermagem foi o curso mais ofertado, como apontam os resultados.

No estado de São Paulo, em relação ao ano de 2018, o número de matrículas da educação profissional subsequente ao ensino médio cresceu 10,2 \% (Instituto Nacional de Estudos e Pesquisas Educacionais Anísio Teixeira - INEP, 2019). Ao contrário, no mesmo ano, no Brasil, a matrícula, nas modalidades concomitante e a integrada ao ensino médio, com 8,0\% e 5,5\%, respectivamente, foram as que tiveram maior aumento (Instituto Nacional de Estudos e Pesquisas Educacionais Anísio Teixeira - INEP, 2018).

As discussões acerca das modalidades de oferta dos cursos técnicos são complexas e precisam ser compreendidas no cenário capitalista que atualmente se encontra sob a égide da lógica neoliberal. A perspectiva do ensino médio integrado se relaciona à articulação entre formação geral e profissional como possibilidade da educação da classe trabalhadora não se restringir aos ditames mercadológicos. Será muito importante, para a área da saúde e, especificamente da enfermagem, dada a sua representatividade, desnaturalizar a ideia de que os cursos da área da saúde necessariamente serão subsequentes. Provavelmente, uma das hipóteses para essa naturalização tenha relação com Programas importantes que foram instituídos, no sentido de formar os trabalhadores já inseridos nos serviços de saúde que não tinham formação profissional, nem escolaridade suficiente para realização de curso técnico.

Considerando a enfermagem, até os dias atuais, é ainda comum o entendimento relativo à exigência dos alunos que ingressam nessa área terem, no mínimo, 18 anos. Esse entendimento pode ser também outra hipótese, de modo algum isolada, que acaba "justificando" a necessidade de cursos subsequentes, mascarando, de certo modo, o significado político e as implicações mais amplas para a educação da classe trabalhadora. Essa exigência teve relação com o dispositivo legal, Parecer 75/70, que fixou regras para curso de auxiliar de enfermagem "em caráter de urgência" (Ministério da Educação, 1989), o que não mais é vigente. Esse entendimento precisa ser, na atualidade, colocado em questão.

Extrapola o âmbito deste artigo aprofundar a discussão acerca do ensino médio integrado, mas compreender os seus significados para a formação emancipadora e os limites presentes na atual Reforma do Ensino Médio faz-se importante também para as discussões da educação profissional técnica de nível médio do trabalhador da saúde.

Atualmente, em conjuntura político-econômica que vai se configurando desde 2016, considerando a formação dos estudantes, os valores que estruturam a proposta de formação, a articulação da oferta à lógica empresarial competitiva, a Reforma do Ensino Médio está articulada ao movimento do capital em sua perspectiva neoliberal, o que vem se radicalizando no atual governo (DeOliveira, 2020). É fundamental considerar a concepção de ensino médio integrado em seus sentidos filosófico, ético-político, epistemológico e pedagógico, enfocando-a como concepção e práxis condizentes às necessidades da classe trabalhadora para a qual o acesso ao conhecimento sistematizado vem sendo permanentemente negado. Conquistas nessa direção têm sido barradas pelo conservadorismo da classe dominante, tendo em vista a imposição de uma "relação de correspondência entre lugar ocupado na divisão social do trabalho e o nível de escolaridade" (Ramos, 2017).

\section{Conclusão}

A formação dos trabalhadores técnicos da área da saúde se insere no cenário político, econômico e social que marca o Estado de São Paulo como polo econômico do país e internacional. A educação, nesse estado, é pontuada como dimensão importante na lógica de fortalecimento da economia, vista na perspectiva da internacionalização, das parcerias público-privado e da competitividade no cenário global. Lógica essa que se insere na política neoliberal e que trazem consequências para a educação, inserindo a formação de trabalhadores técnicos. 
A conformação da área dos cursos da área da saúde na educação profissional técnica de nível médio se relaciona ao avanço da política neoliberal, marcada pela privatização; pelas parcerias-público-privada, envolvendo financiamento público; pela ampla oferta de curso técnico de enfermagem que têm aderência ao mercado de trabalho, dado ao contingente de trabalhadores; pelo predomínio da modalidade subsequente que compartimentaliza a formação geral-formação profissional, restringindo o foco da formação aos interesses mercadológicos.

Nesse cenário há de ser posta em evidência a contradição entre a formação mercadológica e a necessidade de formação humana, emancipadora, se a lógica for fortalecer o SUS tal como concebido pela Reforma Sanitária, bem como garantir educação à classe trabalhadora. E, mais do que isso, urge fortalecer as lutas em defesa da educação profissional técnica de nível médio na área da saúde a favor do SUS e da emancipação.

Foi possível apreender pontos fundamentais referentes à organização da educação profissional técnica de nível médio na área da saúde no estado de São Paulo, que permitiram colocar em destaque a magnitude da enfermagem. Os conhecimentos produzidos podem ser relevantes para o ensino, a gestão e a elaboração de políticas públicas.

\section{Referências}

Assembléia Legislativa do Estado de São Paulo. Decreto n. 53.848, de 19/12/2008 - 53848/08. , (2008). Diário Oficial do Estado de São Paulo.

Bonfim, M. I., Rummert, S. M., \& Goulart, V. M. (2017). Educação profissional em saúde: o sentido da escola pública e democrática. Revista Cocar, 11(21), 322-343. https://periodicos.uepa.br/index.php/cocar/article/view/1294

DeOliveira, R. (2020). A Reforma do Ensino Médio como expressão da nova hegemonia neoliberal. Educação Unisinos, 24(1), 1-20. https://doi.org/10.4013/edu.2020.241.05

Estado de São Paulo. (2016). Lei n. 16.279, de 08 de julho de 2016. https://www.al.sp.gov.br/repositorio/legislacao/lei/2016/lei-16279-08.07.2016.html

Estrela, C. (2018). Metodologia científica: ciência, ensino, pesquisa (3rd.). Artes Médicas.

Governo do Estado de São Paulo, Secretaria da Saúde, \& Gabinete do Secretário - Assistência Técnica Administrativa 1. (2019). Plano Estadual de Saúde (PES) 2020-2023. https://www.documentos.spsempapel.sp.gov.br/sigaex/public/app/autenticar?n=1500112-210

Machado, M. H., Aguiar, W. F., DeLacerda, W. F., DeOliveira, E., Lemos, W., Wermelinger, M., \& Barbosa, C. (2016). Características gerais da enfermagem: o perfil sócio demográfico. Enfermagem em Foco, 7(ESP), 9. https://doi.org/10.21675/2357-707X.2016.v7.nESP.686

Melo, A. A. S. de, \& Sousa, F. B. de. (2017). A agenda do mercado e a educação no governo Temer. Germinal: Marxismo e Educação em Debate, 9(1), 25. https://doi.org/10.9771/gmed.v9i1.21619

Ministerio da Educação. (2011). Decreto n. 6.094, de 24 de abril de 2007 (pp. 1-5). pp. 1-5. Brasília: Diário Oficial da União. http://www.planalto.gov.br/ccivil_03/_ato2007-2010/2007/decreto/d6094.htm

Ministério da Educação. Currículos Mínimos de $2^{\circ}$ Grau das Habilitações Profissionais. Saúde. , (1989).

Ministério da Educação. (2016). Catálogo Nacional de Cursos Técnicos - CNCT. In Ministério da Educação (Vol. 3). http://portal.mec.gov.br/secretaria-deregulacao-e-supervisao-da-educacao-superior-seres/30000-uncategorised/52031-catalogo-nacional-de-cursos-tecnicos

Ramos, M. (2009). Concepções e práticas pedagógicas nas escolas técnicas do Sistema Único de Saúde: fundamentos e contradições. Trabalho, Educação e Saúde, 7(suppl 1), 153-173. https://doi.org/10.1590/s1981-77462009000400008

Ramos, M. N. (2017). Ensino Médio Integrado: Lutas Históricas e Resistências em Tempos de Regressão. Educação Profissional e Tecnológica em Revista, 1(1), 27-49. https://doi.org/10.36524/ept.v1i1.356

Secretária da Educação. (2011). Decreto n. 57.121, de 11.07.2011. https://www.al.sp.gov.br/repositorio/legislacao/decreto/2011/decreto-5712111.07.2011.html

Secretaria da Educação do Estado de São Paulo. (2014). Censo Escolar Estado de São Paulo Informe 2014. In Censo Escolar Estado de São Paulo Informe 2014. http://www.educacao.sp.gov.br/a2sitebox/arquivos/documentos/967.pdf

Secretaria da Educação do Estado de São Paulo. (2021). Site Oficial. https://www.educacao.sp.gov.br/

Todos Pela Educação; (2021). Quem Somos | Todos Pela Educação - Confira os integrantes! https://todospelaeducacao.org.br/quem-somos/\#o-todos-pelaeducacao 